\title{
Jurnal Penelitian Psikologi
}

http://jurnalfpk.uinsby.ac.id/index.php/jpp

ISSN 2087-3441 (printed) 25499882 (online)

\section{Dukungan Sosial dengan Organization Based Self Esteem pada Generasi Y}

\author{
Edwin Fathur Deriyanto ${ }^{1}$, Suryani ${ }^{1}$ \\ ${ }^{1}$ Fakultas Psikologi dan Kesehatan UIN Sunan Ampel Surabaya
}

DOI: http://doi.org/10.29080/jpp.v11i2.456

\begin{abstract}
Organization based self-esteem (OBSE) is the belief that individuals have the ability and confidence in participating and doing work in the organization. The purpose of this study was to study the correlation between social support and organization-based self-esteem. 100 respondents have criteria as the Y generation and actively working in the Sidoarjo district. The sample is chosen by the accidental sampling technique. The product-moment correlation was data analysis used. The results showed that the higher the social support, the higher the organization-based self-esteem. The dynamics of organization-based self-esteem formation and more various characteristics of respondents can be a consideration for further research.
\end{abstract}

Kata kunci : Social Support, Organization Based Self Esteem, Y Generation

\begin{abstract}
Abstrak : Organization based self-esteem (OBSE) adalah kepercayaan bahwa individu memiliki kemampuan dan keyakinan dalam berpartisipasi dan melakukan pekerjaan di dalam organisasi. Tujuan penelitian ini adalah untuk melihat hubungan antara dukungan sosial dengan organization based self esteem. Subjek penelitian ini berjumlah 100 orang yang memiliki kriteria sebagai generasi Y yang aktif bekerja di kabupaten Sidoarjo. Pengambilan sampling menggunakan accidental teknik sampling. Analisis data dalam penelitian menggunakan korelasi product moment. Hasil penelitian menunjukkan bahwa semakin tinggi dukungan sosial maka semakin tinggi pula organization based self esteem yang dimiliki. Dinamika terbentuknya organization based self esteem pada responden yang variatif dan karakteristik responden yang lebih bervariasi dapat menjadi pertimbangan untuk penelitian selanjutnya
\end{abstract}

Kata kunci : Dukungan Sosial, Organization Based Self Esteem, Generasi Y

\section{Pendahuluan}

Organization based self-esteem (OBSE) adalah tingkat kepercayaan bahwa individu memiliki kemampuan dan keyakinan dalam berpartisipasi dan melakukan pekerjaan di dalam organisasi (Bowling, Eschleman,Kirkendall, \& Alarcon, 2010). Dalam konteks organisasi hal itu berfungsi untuk mendukung kemampuan individu dalam menyelesaikan

Corresponding Author: Edwin Fathur Deriyanto (e-mail: efderiyanto@gmail.com) Program Studi Psikologi Fakultas Psikologi dan Kesehatan UIN Sunan Ampel Surabaya, Jl. A. Yani 117 Surabaya Jawa Timur, Indonesia 60237 
tugas-tugasnya (Armenakis, Harris \& Mossholder, 1993). Secara konsep self-esteem merupakan aspek psikologis yang mempengaruhi kemampuan pekerja agar mampu terampil menyelesaikan pekerjaannya dan sanggup mencapai kinerja yang baik (Conley, 2006). Pekerja yang memiliki OBSE tinggi akan merasa dirinya penting, berarti, dan dihargai di dalam organisasi tempat mereka bekerja (Pierce, dkk 1989; Bowling, dkk 2010).

Pierce dan Gardner (2004) menyatakan bahwa ada tiga faktor yang berpengaruh terhadap organization based self-esteem yaitu struktur di tempat kerja, umpan balik dari lingkungan atau dukungan sosial (kepercayaan, keadilan, rasa hormat), dan pengalaman sukses. Struktur tempat kerja mempengaruhi harga diri dalam organization based selfesteem yang dimiliki anggota organisasi. Organisasi yang memiliki sifat tersruktur dan terkontrol, cenderung memberi sugesti kepada anggota bahwa mereka tidak kompeten. Demikian pula dengan dukungan sosial berupa umpan balik yang dikirimkan lingkungan sosial memiliki efek yang sangat besar dalam organization based self-esteem yang dimiliki anggota organisasi. Dukungan sosial dalam organisasi meningkatkan harga diri pada anggota dalam organisasi (Pierce \& Gardner, 2015). Selanjutnya faktor pengalaman sukses yang dimiliki individu dapat meningkatkan efikasi diri yang berdampak pada harga diri dalam konteks organisasi (pierce \& Gardner, 2004). Individu yang memiliki citra diri positif, melibatkan perilaku maupun sikap dalam organisasi (Pierce \& Gardner, 2004).

Salah satu faktor yang berpengaruh terhadap organization based self-esteem adalah dukungan sosial. Dukungan sosial dilihat sebagai suatu bentuk kebersamaan dalam lingkup sosial yang memberikan beberapa bentuk dukungan material, emosional, dan informasi (Lazarus, 1991). Penelitian Almasitoh (2011) menunjukkan bahwa dukungan sosial dapat diperoleh dari orang-orang sekitar seperti keluarga, teman, pasangan, tetangga, sahabat, rekan kerja ataupun individu dalam masyarakat (Sarafino, 1990). Penelitian Alsacia (2011) juga menegaskan bahwa dukungan sosial dapat bersumber dari jaringan sosial atau relasi individu seperti lingkungan pekerjaan dan keluarga.

Dukungan sosial adalah faktor yang sangat penting dalam pembentukan organization based self-esteem. Ketika individu mendapatkan dukungan sosial yang berbentuk dukungan emosional seperti kepercayaan, perhatian, dan rasa cinta maka mereka akan merasa nyaman dan yakin dalam mengerjakan tugasnya. Romadona (2018) menambahkan bahwa orang sekitar dan kondisi situasional sangat berperan dalam pembentukan self-esteem. Setelah individu mendapatkan dukungan sosial maka produktivitas, motivasi, dan kepuasan kerja, dan komitmen terhadap organisasi menjadi meningkat. Semua itu tentunya akan berdampak pada organization based self-esteem individu dalam organisasi.

Menurut Romadona (2018) kondisi lingkungan yang mekanistik akan menghasilkan self esteem yang rendah, sedangkan kondisi lingkungan yang sosial organis atau disebut demokratis lebih menghasilkan self esteem yang tinggi dalam konteks organisasi dan pekerjaan. Hal itu terjadi karena organisasi menempatkan kepercayaan pada karyawan sebagai individu yang berkompeten, berkontribusi dan berharga. Dukungan sosial dapat berasal dari atasan, rekan kerja, dan keluarga (Parasuraman, 1992). Selanjutnya Lane (2004) menambahkan bahwa konsep dukungan sosial adalah kesediaan rekan kerja untuk saling membantu dalam menyelesaikan tugas. Manfaat dari dukungan sosial adalah dapat mengurangi depresi, kecemasan dan juga gejala yang mengganggu individu (Alsacia, 2011).

Dalam organisasi perusahaan dan dunia kerja pada abad 21 saat in sedang dikuasai oleh tiga generasi, yaitu Baby Boomers, Generasi X dan Generasi Y. Generasi Baby Boomers adalah meraka yang lahir antara tahun 1964 sampai 1946 . Sementara yang lahir pada tahun 1965 sampai tahun 1979 disebut Generasi X. Generasi Y lahir mulai tahun 1980 sampai 1999. Generasi Y ini adalah generasi yang mahir untuk menggunakan teknologi, dalam bekerja mengedepankan fleksibilitas, mementingkan sebuah keseimbangan dalam hal pekerjaan dan kehidupan, dan ketika ada hal yang tidak sesuai dengan prinsip, dengan mudah akan berpindah dan akan mencari pekerjaan yang lebih sesuai. Selain dari itu 
generasi Y juga mempunyai self-esteem yang lebih tinggi jika dibandingkan dengan generasi sebelumnya (Twenge \& Campbell, 2008). Individu-individu yang mendapatkan dukungan sosial yang tinggi akan mendapatkan hal-hal bersifat positif di dalam kehidupannya, diyakini mempunyai self-esteem yang tinggi dan juga self-concept yang baik pula. Tujuan dari penelitian ini adalah untuk mengetahui hubungan antara dukungan sosial dengan organization based self-esteem pada generasi Y.

\section{Metode Penelitian}

Penelitian ini menggunakan desain penelitian kuantitatif korelasional. Populasi penelitian adalah generasi $\mathrm{Y}$ di kabupaten Sidoarjo yang berjumlah 718.000 (http//bps.go.id: 3 Februari 2019) dengan rentang tahun kelahiran antara tahun 19801999 dan sedang bekerja di dunia idustri wilayah Sidoardjo. Alasan menjadikan kota Sidoarjo sebagai wilayah penelitian adalah karena Sidoarjo memiliki jumlah industri besar terbanyak di provinsi jawa timur. Teknik pengambilan sampel yang dilakukan adalah Incidental Sampling. Instrumen yang digunakan adalah skala organization based self esteem dan skala dukungan sosial. Adapun teknik analisis yang digunakan ialah analisis Product Moment.

\section{Hasil Penelitian}

Subjek penelitian berjumlah 100 responden yang terdiri dari 81 laki-laki dan 19 perempuan. Tabel 1 menunjukkan bahwa responden perempuan memiliki nilai organization basel self esteem yang lebih tinggi dibandingkan responden laki-laki. Dukungan sosial juga lebih banyak dimiliki oleh responden perempuan dengan nilai 79,2632 sedangkan laki-laki 78,8765. Dengan kata lain responden perempuan lebih tinggi tingkat dukungan sosial daripada responden laki-laki.

Tabel 1

Analisis Deskriptif Berdasarkan Jenis Kelamin

\begin{tabular}{lcccc}
\hline \multicolumn{1}{c}{ Variabel } & Jenis Kelamin & Jumlah & Mean & St. Dev \\
\hline Organization Based Self Esteem & Laki-laki & 81 & 34,6914 & 6,07586 \\
\cline { 2 - 5 } & Perempuan & 19 & 35,2222 & 6,12186 \\
\hline Dukungan Sosial & Laki-laki & 81 & 78,8765 & 0,42879 \\
& & & & \\
\cline { 2 - 5 } & Perempuan & 19 & 79,2632 & 1,23409
\end{tabular}

Ada empat kelompok data berdasarkan rentang tahun kelahiran tahun 1980-1985 ada 2 orang, tahun 1986-1990 ada 17 orang, tahun 1991-1995 ada 56 orang, tahun 19961999 ada 25 orang. Tabel 2 menunjukkan bahwa responden dengan tahun lahir 1986-1990 memiliki tingkat organization basel self esteem yang paling tinggi dibandingkan mereka dengan tahun kelahiran lainnya. Dukungan sosial tertinggi ada pada responden yang memiliki tahun lahir 1986--1990 dengan nilai 80,5685. 
Tabel 2

Analisis Deskriptif Berdasarkan Tahun Lahir

\begin{tabular}{|c|c|c|c|c|}
\hline Variabel & Tahun Lahir & Jumlah & Mean & St. Dev \\
\hline \multirow[t]{4}{*}{ Organization Based self Esteem } & $(1980-1985)$ & 2 & 34,6786 & 7,6567 \\
\hline & $(1986-1990)$ & 17 & 35,5784 & 10,9342 \\
\hline & $(1991-1995)$ & 56 & 34,7778 & 8,7231 \\
\hline & (1996-1999) & 25 & 34,9897 & 8,7986 \\
\hline \multirow[t]{4}{*}{ Dukungan Sosial } & $(1980-1985)$ & 2 & 79,3422 & 12,4867 \\
\hline & $(1986-1990)$ & 17 & 80,5685 & 17,5267 \\
\hline & (1991-1995) & 56 & 79,7344 & 14,3268 \\
\hline & $(1996-1999)$ & 25 & 79,5436 & 13,7377 \\
\hline
\end{tabular}

Analisis data diskriptif berdasarkan pendidikan terakhir dikelompokkan menjadi kelompok SMA sebanyak 35 orang, SMK 60 orang, dan S1 sebanyak 5 orang. Tabel 3 menjelaskan responden yang memiliki pendidikan terakhir S1 mempunyai nilai tingkat organization basel self esteem yang lebih tinggi daripada responden SMA dan SMK. Pada variabel dukungan sosial nilai rata-rata tertinggi adalah responden S1 dengan nilai 81,2237 dan paling rendah SMA dengan nilai 79,9495. Dengan kata lain responden yang memliki pendidikan terakhir S1 lebih tinggi tingkat dukungan sosial daripada responden yang memiliki pendidikan terakhir SMA atau SMK.

Tabel 3

Analisis Deskriptif Berdasarkan Pendidikan Terakhir

\begin{tabular}{ccccc}
\hline Variabel & $\begin{array}{c}\text { Pendidikan } \\
\text { Terakhir }\end{array}$ & Jumlah & Mean & St. Dev \\
\hline Organization Based Self Esteem & SMA & 35 & 34,5647 & 15,4332 \\
\cline { 2 - 5 } & SMK & 60 & 34,3020 & 46,7547 \\
\cline { 2 - 4 } Dukungan Sosial & S1 & 5 & 36,5423 & 25,7615 \\
& SMA & 35 & 79,9495 & 17,6567 \\
\cline { 2 - 5 } & SMK & 60 & 80,4324 & 35,2134 \\
\cline { 2 - 5 } & S1 & 5 & 81,2237 & 21,7726 \\
\hline
\end{tabular}

Analisis diskriptif berdasarkan lama bekerja menampilkan 12 responden yang bekerja kurang dari satu tahun, 20 orang 1 sampai 2 tahun, 31 orang 2 sampai 3 tahun, 23 orang 3 sampai 4 tahun, 14 orang 4 sampai 5 tahun, dan 5 orang yang bekerja lebih dari 5 tahun.

Tabel 4

Analisis Deskriptif Berdasarkan Lama Bekerja

\begin{tabular}{ccccc}
\hline Variabel & Lama Bekerja & Jumlah & Mean & St. Dev \\
\hline Organization Based Self Esteem & $<1$ tahun & 12 & 33,6314 & 35,7366 \\
\cline { 2 - 4 } & $1-2$ tahun & 20 & 33,3728 & 6,6346 \\
\cline { 2 - 4 } & $2-3$ tahun & 31 & 34,4230 & 10,5244 \\
\cline { 2 - 4 } & $3-4$ tahun & 23 & 34,6425 & 45,6377 \\
\cline { 2 - 4 } & $4-5$ tahun & 14 & 35,8376 & 9,7725 \\
\cline { 2 - 4 } Dukungan Sosial & $>5$ tahun & 5 & 34,6354 & 65,6344 \\
\hline & $<1$ tahun & 12 & 80,4237 & 56,6276 \\
\hline & $1-2$ tahun & 20 & 80,5424 & 17,5269 \\
\hline & $2-3$ tahun & 31 & 80,1527 & 5,6274 \\
\hline & $3-4$ tahun & 23 & 80,5232 & 26,7675 \\
& $4-5$ tahun & 14 & 81,5267 & 42,6276 \\
\hline & $>5$ tahun & 5 & 82,7367 & 33,6735 \\
\hline
\end{tabular}

Pada tabel 4 terlihat bahwa responden yang bekerja selama empat sampai lima tahun mempunyai nilai tingkat organization basel self esteem yang lebih tinggi daripada 
responden yang lainnya. Demikian pula dengan dukungan sosial dmana responden yang bekerja selama lima tahun memiliki tingkat dukungan sosial yang lebih tinggi daripada responden yang lainnya.

Tabel 5 menunjukkan bahwa terdapat hubungan positif antara dukungan sosial dengan organization based self esteem. Nilai korelasi sebesar 0,760 dengan nilai signifikansi 0,000 .

Tabel 5

Korelasi Variabel Organization based Self Esteem dengan Dukungan Sosial

\begin{tabular}{ccc}
\hline Variabel & Nilai Korelasi & Sig. \\
Organization Based Self Esteem dengan Dukungan & 0,760 & 0,00 \\
Sosial & & \\
\hline
\end{tabular}

\section{Pembahasan}

Hasil penelitian menunjukkan hubungan antara dukungan sosial dengan organization based self-esteem. Hasil tersebut mengindikasikan bahwa semakin tinggi nilai dukungan sosial dari rekan kerja maka akan semakin meningkatkan organization based self esteem. Hal itu juga dikatakan oleh Ibrahim (2014) bahwa dukungan rekan kerja dapat memprediksi organization based self-esteem pegawai. Semakin individu mendapatkan dukungan sosial maka secara otomatis tingkat organization based self-esteem juga akan ikut tinggi. Dukungan sosial meningkatkan harga diri invidu untuk lebih maksimal dalam mengerjakan tugas dan juga akan lebih produktif.

Hasil penelitian ini juga menunjukkan bahwa mereka yang mendapatkan dukungan sosial paling banyak juga memiliki organization based self-esteem yang baik. Saat individu mendapatkan dukungan sosial seperti kepercayaan, maka hal itu membuat dirinya juga semakin percaya dengan kemampuan dan kompetensi diri untuk mengerjakan suatu pekerjaan. Romadona (2018) juga mengatakan bahwa harapan orang-orang di sekitar dan kondisi situasional sangat berperan dalam pembentukan self-esteem. Setelah individu mendapatkan dukungan sosial maka individu dapat meningkatkan produktivitas, motivasi, kepuasan kerja, dan komitmen yang semua itu adalah dampak dari organization based selfesteem. Ketika individu mendapatkan dukungan sosial dari rekan kerja yang berbentuk dukungan emosional seperti rasa percaya, perhatian, dan rasa cinta maka individu tersebut akan merasa nyaman dan yakin dalam melakukan kegiatan-kegiatan yang dikerjakan termasuk dalam konteks pekerjaan.

Individu yang mendapatkan dukungan sosial akan terdorong untuk lebih baik dalam menyelesaikan tugasnya karena adanya bantuan dari orang sekitar. Harga diri mereka pun meningkat karena merasa dapat memberikan kontribusi yang terbaik bagi organisasi. Mereka yang memiliki OBSE tinggi akan merasa bahwa dirinya penting, berarti, dekat, dan dihargai ketika berada di dalam ruang lingkup organisasinya (Armenakis, dkk, 1993). Hal tersebut didasarkan pada konsep bahwa self-esteem merupakan aspek psikologis yang dapat mempengaruhi pekerja agar terampil menyelesaikan pekerjaannya untuk dapat mencapai kinerja yang baik. Hal itu juga dikatakan oleh Conley (2006) bahwa jika individu mendapatkan dukungan sosial yang tinggi maka mereka akan memiliki OBSE yang tinggi jrta meningkatkan perasaan dirinya penting, berarti, dan dihargai.

Penelitian ini menggunakan konteks industri sehingga dukungan sosial yang didapatkan adalah dari ruang lingkup organisasi yaitu teman-teman kerja. Dukungan sosial yang didapatkan dapat meningkatkan produktivitas kerja, motivasi, kepuasan kerja, dan komitmen terhadap organisasi. Individu akan terdorong untuk lebih baik dalam menyelesaikan tugasnya karena merasa diperhatikan dan terbantu. Skinner (2013) dalam teori reinforcement juga menjelaskan bahwa individu yang yang mendapatkan penguatan 
positif maka akan melakukan pengulangan terhadap perilaku yang dilakukan. Penguatan positif dalam hal ini adalah dukungan sosial yang berbentuk dukungan emosional, penghargaan, informasi, dan instrumental. Jika hal tersebut diberikan berulang-ulang maka akan meningkatkan keyakinan untuk berpartisipasi dan mampu melakukan pekerjaan sesuai perannya dalam organisasi.

Pemberian dukungan sosial dari rekan kerja adalah bentuk dari lingkungan yang demokratis. Motivasi dan perhatian adalah bentuk dukunganyang membuat individu nyaman sehingga memfasilitasi mereka untuk dapat menyelesaikanngan optimal. Romadona (2018) juga menegaskan bahwa kondisi lingkungan yang sosial organis atau disebut demokratis lebih menghasilkan pekerja dengan self-esteem yang tinggi dalam konteks organisasi. Hal itu dapat terjadi karena organisasi percaya bahwa karyawannya dalah individu kompeten, berharga dan memiliki kontribusi.

\section{Simpulan dan Saran}

Semakin tinggi dukungan sosial yang diterima individu maka semakin tinggi pula organization based self- esteem yang dimiliki. Dukungan sosial yang diberikan berulangulang akan meningkatkan keyakinan individu untuk berpartisipasi dan melaksanakan perannya dalam organisasi. Sejumlah faktor demografis juga terlihat memberikan perbedaan pada tingkatan organization based self esteem yang dimiliki pekerja. Demikian pula dengan dukungan sosial yang juga bervariasi dilihat dari data demografis yang berbeda. Adapun dampak variasi dukungan sosial yang diterima akan membuat dirinya semakin percaya dengan kemampuan dan kompetensi diri yang dimiliki.

Penelitian ini hanya memopret hubungan variabel dukungan sosial dengan organization based self esteem secara kuantitatif. Data statistik hanya memberikan gambaran hubungan kedua variable dengan tambahan tabel demografis responden. Observasi dan wawancara akan lebih dapat menggali faktor-faktor yang lain yang mungkin dapat berperan dalam hal organization based self esteem sehingga mendapatkan gambaran yang lebih luas dan menyeluruh tentang bentuk-bentuk dukungan sosial yang diterima. Selain itu dinamika terbentuknya organization based self esteem pada responden yang variatif juga dapat terlihat. Tambahan karakteristik responden agar lebih bervariasi juga dapat menjadi pertimbangan untuk penelitian selanjutnya.

\section{Daftar Pustaka}

Ade, I. P. \& Ilhamudin, dkk (2015). Pengaruh Perceived Organizational Support dan Organization Based Self Esteem terhadap Work Engagement, Jurnal Psikologi, volume 1, 40-50.

Adi, I. (2012). Pengaruh Organization Based Self Esteem terhadap Komitmen Organisasional dan dampaknya pada Kinerja karyawan, jurnal, volume 8.

Almasitoh, U. H. Stres Kerja Ditinjau dari Konflik Peran Ganda dan Dukungan Sosial pada Perawat, Jurnal Psiologi Islam, Volume 8 No. 163-82.

Alsacia, J. 2011. Hubungan Antara dukungan Sosial Dengan Stres Kerja Pada Karyawan. Skripsi. Surakarta : Universitas Muhammadiyah Surakarta.

Apollo \& Cahyadu, A. (2012). Konflik Peran Ganda Perempuan Menikah yang Bekerja Ditinjau dari Dukungan Sosial Keluarga dan Penyesuaian Diri, Widya Warta No. 02 Tahun XXXV.

Armenakis, A. A., Harris SG. \& Mossholder, K. (1993). Creating readiness for organizational change, Human Relations, 46, 681-703.

Azwar, S. (2011). Reliabilitas dan Validitas, Pustaka Pelajar

Bowling, N. A. (2010) A Meta-Analytic Examination of thr Relationship between Job Stasfaction and Subjective Well Being, Journal of Psychology. 
Chen, M. F., dkk (2016). Organization-based self-esteem mediates the effects of social support and job satisfaction on intention to satay in nurses, Journal of Management, volume 24, Issue 1.

Conley. (2006). Breaking Free from the Anxiety Trap. Oktober 04, 2009.

Data Penduduk Sidoarjo. Diunduh 3 Februari 2019, daru BPS: http://bps.go.id.

Employee Turnover. Diunduh 20 Oktober, dari CH2MHILL: https://www.ch2m.com/corpporate/sr/society/employee-turnover.asp

Eisner, S. P. (2005). Managing Generation Y. Advanced Managament Journal, 4-15.

Farok, A. F. A. \& Zainal M. R. S. (2017). Talent Management At Service Sector : Linking Organizational Based self esteem To servant Leadership, Interactional Justice and Job Dedication, Journal of Scientific Research, Volume 10. Issue 4, 363-371.

Ganster, D. C., Fusilier, M. R., \& Mayes, B. T. (1986). Role of social support in the experience of stress work, Journal of Psychology.

Hadi, Sutrisno. (2000). Metodologi research. Yogyakarta, Andi Yogyakarta.

Heydrarian, M. \& Abhar, S. (2011). Factors contributing to employees turnover intention, Segi Review Vol. 04 no.2.

Husein umar, (2009). Metode penelitian untuk skripsi dan tesis bisnis, Jakarta, Rajawali Pers, 78.

Ibrahim, I. H. (2014). The relationship Between Job Stress, Co-Worker Support and Organization Based Self Esteem : A Survey Across Different Occupations, Journal of Art, Science \& Commerce, Volume V, Issue 2.

Isnawati, D. \& Suhariadi, F. (2013). Hubungan Antara Dukungan Sosial Dengan Penyesuaian Diri Masa Persiapan Pensiun, Jurnal Industri dan Organisasi, 1-6.

Korman, A. K. (1970). Toward an hypothesis of work behavior. Journal of Applied Psychology, 54: 31-41.

Korman, A. K. (1971). Organizational achievement, aggression and creativity: Some suggestions toward an integrated theory. Organizational Behavior and Human Performance, 6. 593-613.

Lan, K. (2004). TheNew Strategic Management : Organization, Co-creatin Unique.

Lane, J., Lane, A. M., \& Kyprianou, A. (2004). Self-efficacy, self-esteem and their impact on academic performance. Social Behavior and Personality: An international journal, 32(3), 247-256.

Lazarus, R. S. (1991). Emotion and Adaptation, New York, Oxford University Press.

Low, A. (2013, Maret 14). Worker turnover rate rising. says Hay study.

Margono, (2004). Metodologi Penelitian Pendidikan, Jakarta, PT. Rineka Cipta.

Mathis, L. R. \& Jackson, H. J. (2001). Manajemen Sumber Daya manusia, Jakarta, Buku Kedua.

Mercer Talent Consulting \& Information Solution. Diunduh 25 Oktober, 2018, dari http://swa.co.id/swa/trends/managememnt/turnover-talent-tinggi-ini-diapemicunya-survei.

Parasuraman, A. (1991). Marketing Service:Competing Through, New York Free Press.

Pierce, J. L, \& Gardner, D. G, (2004), Self esteem within the work and organizational contect: A review of the organization-based self-esteem literature, Journal of management, 591-622.

Quick, J. C., \& Quick, J. D. (1984). Organizational stress and preventive management, New York, McGraw-Hill.

Rivai, A. (2001). Media Pengajaran, Bandung, CV Sinar Baru.

Romadona, M. R. (2018). Peran Harga Diri dalam Organisasi dan Komunikasi Organisasi terhadap Keterlibatan Kerja Peneliti di suatu Lembaga Riset, Jurnal Pekommas, Volume 3 No. 2.

Sarafino, E. P. (1990). Health Psychology: Biopsychosocial Interactions. New York: John Willey \& Sons, Inc. 
Schaufeli \& Bakker, (2006). Dr Jekyll or Mr Hide? On The Differences Between Work Engagement and Workaholism, USA and UK, Edward Elgaard Publishing.

Skinner, B. F. (2013). Ilmu pengetahuan dan perilaku manusia. Yogyakarta; Pustaka Pelajar. Thoits. (1986). Social support as coping assistance. Journal of Consulting and Clinical Psychology, 54, 416-423.

Toly, A. (2001). Analisis Faktor-Faktor yang Mempengaruhi, Turnover Intention pada Staff Publik, Jurnal Bisnis.

Twenge, J. M., \& Campbell, S. M. (2008). Generational Differences in Phychological Traits and Their Impact on the Workpace. Journal of Managerial Psychology, 862-877.

Yang, Z. \& Zhang H. dkk (2018). Crossover Effects of Servant Leadhership and Job Social Support on Employee Spouses: The Mediating Role of Employee Organization Based Self Esteem, Journal of Business Ethics, Volume 147, Issue 3.

Zemke, R, Raines, C, \& Filipczak, B. (2000). Generation at Work Managing the Clash of Veterans, Boomers, Xers anf Nexters in your workplace. New York : American Management Association. 